Raeesa MOOLLA

Nico KOTZE

Liz BLOCK

\title{
Zadovoljstvo s stanovanji v naselju Braamfischerville $v$ Sowetu in kakovost življenja v njih: študija primera iz Južnoafriške republike
}

Vlada afriškega nacionalnega kongresa (ang. African $\mathrm{Na}$ tional Congress ali ANC) se je v okviru programa rekonstrukcije in razvoja odločila za gradnjo, da bi zagotovila stanovanja nekdanjim socialno šibkejšim skupinam in rešila vprašanje velikih zaostankov v stanovanjski gradnji, ki so zadnja leta značilni za Južnoafriško republiko. Kljub dobrim namenom pa so ta stanovanja tarče ostrih kritik zaradi nizkih gradbenih standardov in slabe kakovosti ter tudi pomanjkanja osnovnih storitev in javnih dobrin na območju novogradenj. Raziskava, na podlagi katere je nastal ta članek, je bila opravljena leta 2008, v njej pa so sodelovali prebivalci območja Braamfischerville v Sowetu. $S$ pomočjo vprašalnika smo za vsako gospodinjstvo med drugim zbrali demografske podatke ter podatke o mesečnih dohodkih in stroških. Stopnjo zadovoljstva $s$ posameznimi prvinami stanovanja, kot so okna, vrata in streha, in tudi s samim stanovanjem na splošno, smo določili s pomočjo petstopenjske Likertove lestvice in intervjujev. Pri določanju dejavnikov, ki prispevajo k večjemu zadovoljstvu, smo ugotovili, da je bližina osnovnih storitev in javnih dobrin za stanovalce enako pomembna kot videz stanovanja. V bližini novozgrajenih naselij je zato treba zagotoviti osnovne javne dobrine. Stanovalci so se pritoževali nad kakovostjo stanovanj in dostopom do osnovnih storitev in javnih dobrin; te znižujejo stopnjo zadovoljstva $s$ stanovanji in tako negativno vplivajo na kakovost življenja prebivalcev naselja Braamfisherville.

Ključne besede: zadovoljstvo s stanovanji, storitve, javne dobrine, Soweto, Južnoafriška republika 


\section{Uvod}

Nekdanji zakoni apartheida v Južnoafriški republiki, ki so večini državljanov omejevali svobodo gibanja in izbire bivališča, imajo še vedno negativne posledice na cenovno dostopnost in razpoložljivost stanovanj, zlasti med revnim prebivalstvom. Zaradi slabega načrtovanja in pomanjkljivosti pri zagotavljanju cenovno ugodnih stanovanj za ta del skupnosti je vlada med apartheidom precej zapostavila obubožane temnopolte prebivalce, ki so pomemben delež prebivalstva (Sowman in Urquhart, 1998). Ko so v osemdesetih letih prejšnjega stoletja ukinili zakone, ki so urejali priliv temnopoltega prebivalstva $\mathrm{v}$ urbana območja oziroma omejevali njihovo gibanje, se je stanovanjski problem v državi zaostril. Temnopolti so se lahko prvič svobodno gibali in izbrali kraj bivališča. To je pospešilo priseljevanje na urbana območja, zaradi česar so na praznih zemljiščih okrog teh območij začeli nastajati slumi in ilegalna naselja (ang. squatter camps; Sowman in Urquhart, 1998). Trenutno se v Južnoafriški republiki soočajo $s$ hudim primanjkljajem stanovanj; aprila 2008 je namreč primanjkovalo kar 2,3 milijona stanovanj (Bhengu, 2008).

Leta 1994 je v Južnoafriški republiki oblast prvič prevzela izvoljena demokratična vlada afriškega nacionalnega kongresa (ang. African National Congress, v nadaljevanju: ANC), ki je obljubljala, da bo proračunska sredstva, namenjena stanovanjskemu sektorju, zvišala s slabih dveh na pet odstotkov, s čimer naj bi v petih letih po izvolitvi zgradila milijon stanovanj. Orodje, ki ga je vlada ANC uporabila za to, da bi se država znebila dediščine apartheida in odpravila neenakosti v družbi, ki so škodile prej marginaliziranim in prikrajšanim skupinam, je bil osnovni dokument njene politike, $\mathrm{z}$ naslovom »Program rekonstrukcije in razvoja « (ang. Reconstruction and Development Programme, $\mathrm{v}$ nadaljevanju: RDP), osredotoča pa se na vse vidike preobrazbe (Fitchett, 2001; Donaldson in Marais, 2002). Temelji na šestih osnovnih načelih: 1. gre za integriran in trajnosten program; 2. usmerja ga prebivalstvo; 3 . njegov cilj je vsem zagotoviti mir in varnost; 4. poskuša odpraviti razdrobljeno družbo, razdeljeno na revne in bogate; 5 . poskuša povezati procese obnove, razvoja, rasti in nove delitve in preprečiti, da bi se ti procesi medsebojno spodkopavali, in 6. uteleša proces demokratizacije, v katerem družba (tudi tisti, ki so jih v preteklosti prizadele krivice) prispeva $\mathrm{k}$ spremembam (Donaldson in Marais, 2002).

Uradni statistični podatki o številu stanovanj, zgrajenih $\mathrm{v}$ prvih petih letih izvajanja programa RDP, se močno razlikujejo od prvotno predvidenih ciljev programa. »Kaže, da so med letoma 1994 in 1999 zgradili od 500.000 do 750.000 stanovanj.« (Marais idr., 2002: 381.) Brezdomstvo v Južnoafriški republiki pa zaradi vse višje stopnje brezposelnosti in pomanjkanja cenovno dostopnih stanovanj kljub temu narašča
(O'Leary, 2003). Zaostanki v stanovanjski gradnji in počasna gradnja cenovno ugodnih stanovanj so še povečali vrzel med lastniki stanovanj in prebivalci barakarskih naselij. Zaradi vse slabših okolišcin se je leta 2008 južnoafriška vlada odločila, da bo do leta 2014 letno ponudbo stanovanj povečala z 270.000 na 500.000 stanovanj; načrtuje, da ji bo istega leta uspelo odpraviti tudi ilegalna naselja in slume (urad za stanovanja, 2005, 2006; Bhengo, 2008).

Razprava o zadovoljstvu s stanovanji v naselju Braamfischerville, zgrajenimi v okviru RDP, in kakovosti življenja v njih je razdeljena na tri dele: $\mathrm{v}$ prvem je pozornost namenjena kakovosti stanovanj in gradbenim standardom; $\mathrm{v}$ drugem se obravnava razpoložljivost storitev in javnih dobrin, $\mathrm{v}$ tretjem pa zadovoljstvo s stanovanji in kakovost življenja na preučevanem območju.

\section{Braamfischerville kot območje preučevanja}

Braamfischerville je kraj v Sowetu, južno od Johannesburga. Tamkajšnje stanovanjsko naselje, zgrajeno v okviru RDP, leži na meji med Sowetom in Roodepoortom, vendar spada pod Soweto. Gradnja prvega od štirih sklopov stanovanj v okviru RDP v Braamfischervillu se je začela leta 1996. Leta 2002 so se lotili zadnjih dveh sklopov, v obeh pa so gradili stanovanja, podobna tistim iz prejšnjih dveh. Hiše v teh naseljih se razlikujejo samo po hišnih številkah, ki si v vrstnem redu sledijo po datumu izgradnje (od prvega do četrtega sklopa).

Po navedbah vlade naj bi v teh naseljih poskrbeli za osnovne storitve (na primer za tekočo vodo, kanalizacijo in elektriko) in javne dobrine (na primer šole in ambulante), ki so v vsaki novi skupnosti najpomembnejše. Po poročanju časopisa Sowetan (Mohlala, 2002) pa naj po šestih letih gradnje veliko teh storitev še vedno ne bi bilo urejenih. Poleg tega je bila slabo razvita tudi infrastruktura. $V$ tem sklopu je bila, na primer, na voljo samo ena začasna osnovna šola, ki so jo uredili v zabojnikih; novo osnovno šolo so zgradili šele v tretjem sklopu, medtem ko je bila srednja šola takrat še vedno v izgradnji. Poleg tega soseska ni imela urejenega odvodnjavanja meteornih voda niti odprtih površin oziroma parkov za rekreacijo (Mohlala, 2002). Vlada je šele leta 2008 začela asfaltirati glavne ceste in sosesko urejati s sajenjem dreves ob cestah (Moolla, 2008).

Pri tej študiji primera je vprašalnik izpolnilo dvesto gospodinjstev naselja Braamfischerville iz vsakega od štirih sklopov stanovanj v okviru RDP. V vsakem sklopu je bilo naključno izbranih petdeset gospodinjstev. Demografski podatki gospodinjstev in podatki o njihovem zadovoljstvu s stanovanjem so bili zbrani s pomočjo petstopenjske Likertove lestvice. 


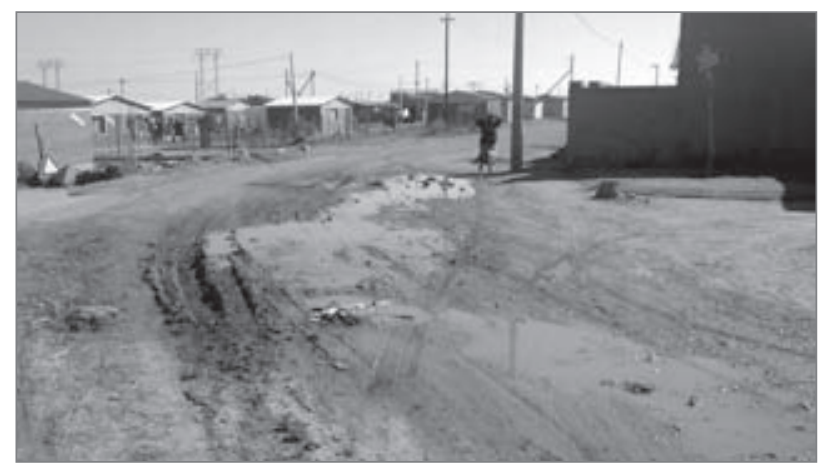

Slika 1: Hiše v žalost zbujajoči soseski naselja Braamfischerville (foto: Nico Kotze)

\section{Značilnosti stanovanj v naselju Braamfischerville}

Značilna hiša, zgrajena v Južnoafriški republiki v okviru programa rekonstrukcije in razvoja, ima $36 \mathrm{~m}^{2}$ površine in se nahaja na parceli, veliki $250 \mathrm{~m}^{2}$ (Thale, 2001; Cox, 2008). Vsaka enota ima spalnico, dnevno sobo in kuhinjo z odprtim tlorisom ter ločeno kopalnico. Običajno so hiše zgrajene iz opeke in malte in imajo pocinkano železno streho, kovinska vrata in navadno dve oziroma tri majhna okna (Pollack, 2003; glej sliko 2). Niso pa vse hiše, zgrajene v okviru RDP, enake; nekatere so večje in lahko merijo do $45 \mathrm{~m}^{2}$. Kot navaja David Pottie (2003), pa je samo 30 \% vseh hiš, ki jih je zgradila vlada, večjih od $30 \mathrm{~m}^{2}$, in le malo hiš, zgrajenih do leta 1999 , je izpolnjevalo standardne gradbene predpise. Po drugi strani pa imajo lokalne in regionalne uprave različne zahteve glede stanovanj, zgrajenih v okviru RDP, kar povzroča opisana odstopanja (Pottie, 2003). Vse hiše imajo dostop do čiste tekoče vode in so priključene na javno kanalizacijo (Thale, 2001; Cox, 2008). Leta 2006 je značilna hiša, zgrajena v okviru RDP, stala približno 45.000 do 50.000 ZAR (1,00 USD = 7,25 ZAR; Cross idr., 2006), vendar ji bo zaradi inflacije čez dve leti verjetno vrednost poskočila.

V Južnoafriški republiki so gradbeni standardi in kakovost stanovanj v ospredju stanovanjske razprave, saj mora vlada še določiti raven sprejemljivih standardov za podizvajalce in investitorje (Bond in Khosa, 2002). Različne skupnosti so vložile številne pritožbe glede varnosti stanovanj, zgrajenih v okviru RDP. Zadnje čase se pojavljajo tudi pomisleki glede vzdržnosti teh skupnosti, saj na novozgrajenih območjih ni potrebne infrastrukture (Rosenberger, 2003). Nekateri teoretiki menijo, da je zadovoljstvo prebivalcev revnejših skupnostih večje pri tistih, ki živijo v domovih, ki so jih zgradili sami (na primer barakah), kot pri tistih, ki živijo v stanovanjih, ki jih je zgradila vlada (Mehlomakulu in Marais, 2000). Vendar to ne drži vedno, saj lahko gotova lastniška pravica, ki pri lastnih gradnjah ni vedno zagotovljena, prav tako vpliva na zadovoljstvo s stanovanji.

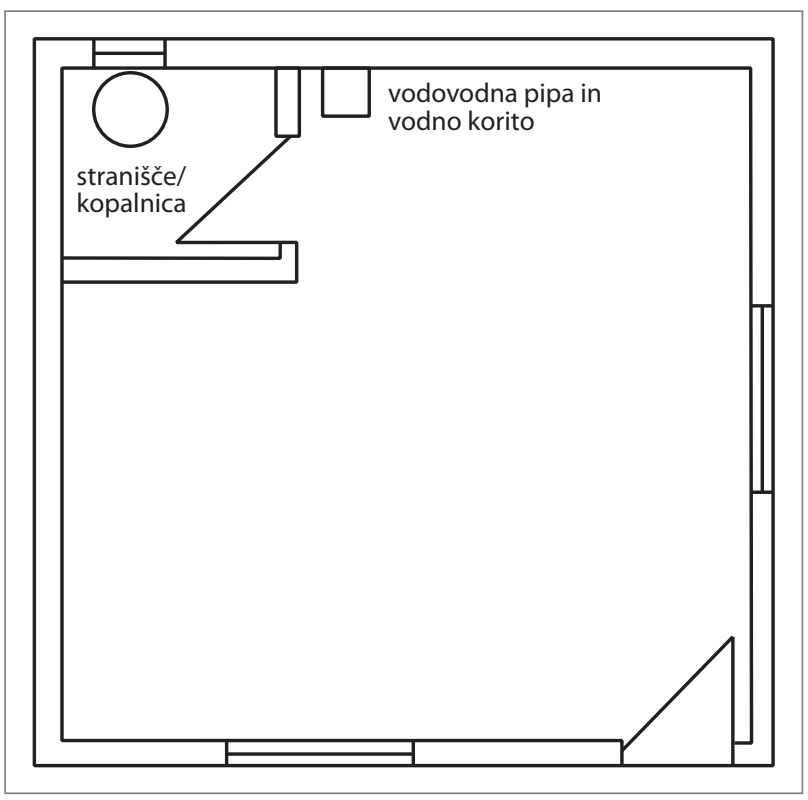

Slika 2: Tloris hiše, zgrajene v okviru RDP v naselju Braamfischerville (ilustracija: Nico Kotze).

Raziskava, ki je leta 2008 potekala v naselju Braamfischerville, je pokazala, da večina stanovalcev enot, zgrajenih $\mathrm{v}$ okviru RDP, ni bila zadovoljna s kakovostjo. Pritoževali so se tako nad strehami in stenami, ki so bile neustrezno zgrajene zaradi slabe kakovosti obrtniških del, kot tudi nad vrati, ki se niso pravilno odpirala in zapirala. Ker pri gradnji niso uporabili prezračevalnih zidakov, so se stanovalci pritoževali nad tem, da morajo nenehno odpirati okna, če želijo stanovanja prezračiti, zaradi česar je nato hiša prašna. Poleg tega so stanovalci izrazili tudi potrebo po ustrezni kuhinji in kopalnici, $55 \%$ anketirancev pa je bilo $s$ stanovanji izredno nezadovoljnih $\mathrm{z}$ vidika njihove primernosti za bivanje. John Turner (1976) navaja, da je za stanovalce vrednost hiše pomembnejša kot njen videz. Poleg tega konstrukcija hiše, tudi če so pri gradnji uporabljeni materiali slabše kakovosti, ne vpliva na posameznikovo mnenje, kadar hiši pripisuje določeno vrednost. To je jasno razvidno tudi iz rezultatov raziskave: čeprav so bili določeni vidiki za anketirance sporni, je bila stopnja njihovega nezadovoljstva s celotnim stanovanjem oziroma hišo nižja. Poleg tega je skoraj $86 \%$ anketirancev poudarilo, da so lastniki oziroma da imajo gotovo lastninsko pravico nad svojimi stanovanji (zgrajenimi v okviru RDP), čeprav jih je bilo 63,6 \% nezaposlenih, 73 \% pa je imelo mesečne dohodke nižje od 1.500 ZAR.

\section{Zadovoljstvo s stanovanji v naselju Braamfischerville}

To poglavje obravnava stopnjo zadovoljstva s stanovanji, zgrajenimi v okviru RDP. Kobus Lazenby (1988: 55) navaja, da »lahko zadovoljstvo $s$ stanovanji opredelimo kot stopnjo zadovoljstva s posamezno hišo znotraj izbranega stanovanjskega, 


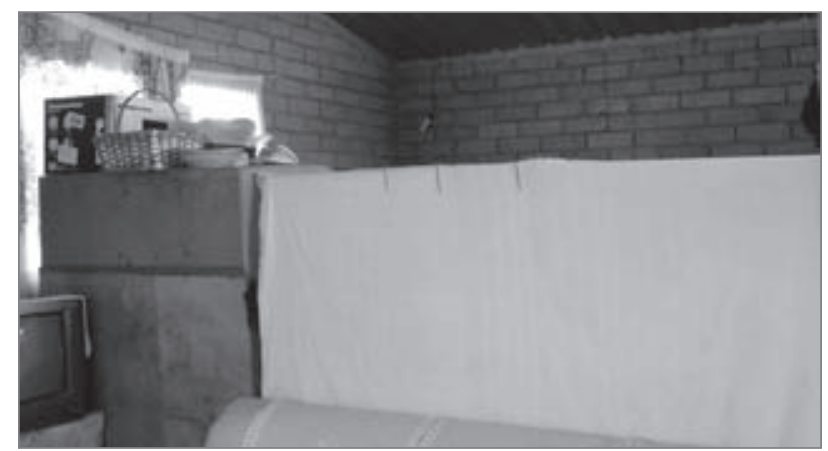

Slika 3: Stanovalci poskušajo ustvariti občutek zasebnosti (foto: Nico Kotze).

fizičnega in družbenega okolja, kot tudi z njenimi specifičnimi lastnostmi«. Najprej je treba poudariti, da so anketirani stanovalci prvi lastniki, ki so pred tem najverjetneje živeli v barakah ali ilegalno naseljevali tuja dvorišča. Kljub temu je iz povprečnih vrednosti v preglednici 1 razvidno, da je večina nezadovoljnih oziroma zelo nezadovoljnih $s$ svojimi hišami, ki so bile zgrajene v okviru RDP. Če pa upoštevamo njihove odgovore glede zadovoljstva $s$ celotno hišo, jih več kot $50 \%$ navaja, da so z njo zadovoljni oziroma zelo zadovoljni. Velja pa poudariti, da gre za prve lastnike, ki so prej živeli v veliko slabših razmerah.

Največ kritik se je nanašalo na velikost hišs, saj je bilo glede tega nezadovoljnih kar $66 \%$ anketirancev. Bruto etažna površina hiš, vključenih $\mathrm{v}$ to raziskavo, je znašala $30 \mathrm{~m}^{2}$, zgrajene pa so bile na parcelah, velikih $250 \mathrm{~m}^{2}$ (Thale, 2001; Cox, 2008). Tak rezultat pa ni nič nenavadnega, saj so anketiranci velikost hiš presojali na podlagi velikosti večine družin in razširjenih družin, ki v njih stanujejo ( $42 \%$ anketirancev je navedlo, da v njihovi hiši živi od pet do deset ljudi). Anketiranci niso bili zadovoljni tudi s strehami brez stropov (60,8\%); okni, ki jih je treba nenehno odpirati, ker pri gradnji niso uporabili prezračevalnih zidakov (61 \%); vrati, ki se težko odpirajo in zapirajo (63,9\%); v nekoliko manjši meri pa tudi s stenami $(53,1 \%)$.Vzrok za te pomanjkljivosti so najverjetneje obrtniška dela slabe kakovosti.

Preglednica 1: Stopnja zadovoljstva s stanovanji, zgrajenimi v okviru RDP v naselju Braamfischerville (\%).

\begin{tabular}{llllll}
\hline Spremenljivke & $\begin{array}{l}\text { Zelo } \\
\text { zadovoljen }\end{array}$ & $\begin{array}{l}\text { Nezado- } \\
\text { voljen }\end{array}$ & $\begin{array}{l}\mathrm{Ne} \\
\text { vem }\end{array}$ & $\begin{array}{l}\text { Zadovo- } \\
\text { ljen }\end{array}$ & $\begin{array}{l}\text { Zelo } \\
\text { zadovoljen }\end{array}$ \\
\hline na splošno & 16,2 & 28,3 & 5,1 & 38,4 & 12,1 \\
\hline velikost & 25,8 & 40,2 & 4,1 & 13,4 & 16,5 \\
\hline streha & 14,4 & 46,4 & 0,0 & 33,0 & 6,2 \\
\hline stene & 5,2 & 47,9 & 1,0 & 39,6 & 6,3 \\
\hline vrata & 13,4 & 50,5 & 2,1 & 32,0 & 2,1 \\
\hline okna & 21,0 & 40,0 & 6,0 & 31,0 & 2,0 \\
\hline kopalnica & 9,0 & 49,0 & 2,0 & 36,0 & 4,0 \\
\hline kuhinja & 28,1 & 45,8 & 2,1 & 13,5 & 10,4 \\
\hline povprečje & 16,6 & 43,5 & 2,8 & 29,6 & 7,5 \\
\hline
\end{tabular}

Stopnji nezadovoljstva s kuhinjo, ki je bila opremljena samo $\mathrm{z}$ vodovodno pipo in s pomivalnim koritom, nameščenim ob zid, ter s kopalnico, opremljeno le s straniščno školjko, ki je bila s stenami ločena od preostalih prostorov, sta znašali $74 \%$ in $58 \%$. Te nizke vrednosti lahko pripišemo slabemu načrtovanju in prizadevanjem odgovornih organov, da stroške gradnje stanovanj v okviru RDP kar najbolj omejijo.

\section{Razpoložljivost storitev in javnih dobrin v naselju Braamfischerville}

Zaradi hitre urbanizacije $\mathrm{v}$ Južnoafriški republiki občinske oblasti ne uspevajo dovolj hitro zagotoviti potrebne infrastrukture in nuditi ustreznih storitev, še zlasti na območjih z velikim deležem revnejših gospodinjstev. Tako so se v ospredje prebili zapleteni problemi, povezanis stanovanjsko politiko, stanovanjskim upravljanjem, porazdelitvijo dohodka in z zagotavljanjem ustrezne infrastrukture in storitev (Westaway, 2006). Turner (1967) navaja, da je za stanovalce bližina osnovnih storitev in javnih dobrin pomembnejša kot videz stanovanja. Bližina javnih dobrin in delovnega mesta je bistvenega pomena zaradi ekonomskih razlogov (denarnih prihrankov) in zadovoljstva stanovalcev. Za družine z nižjimi dohodki veliko stanovanj, ki jih je zgradila vlada, ni na dobri lokaciji, saj morajo veliko zapraviti za prevoz, kar lahko vodi v še hujšo revščino. Zato so neustrezne lokacije javnih stanovanj v Južnoafrǐ̌ki republiki deležne mnogih kritik (Mehlomakulu in Marais, 1999).

Večina anketirancev je na vprašanje o bližini storitev in javnih dobrin v naselju Braamfischerville odgovorila, da so trgovine Spaza (neformalne trgovine; $86 \%$ ), postajališča za taksije $(80 \%)$ in osnovne šole $(78 \%)$ od njihovih domov oddaljeni samo nekaj minut hoje (glej preglednico 2). V nasprotju s postajališči za taksije anketiranci menijo, da so druge oblike javnega prevoza, na primer avtobusna postajališča in postaje (63\%) ter železniške postaje (6\%), bolj oddaljeni oziroma slabše dostopni.

Leta 2002 je bila edina šola v naselju Braamfischerville osnovna šola Mosesa Khotaneja, še vedno pa je urejena v začasnem objektu. V soseski je bila nato zgrajena nova osnovna šola ( $\mathrm{v}$ tretjem sklopu). $38 \%$ anketirancev je odgovorilo, da se srednje šole nahajajo blizu doma (po letu 2002 je bila na tem območju zgrajena ena srednja šola). Le $18 \%$ jih je menilo, da so vrtci samo nekaj minut hoje stran od doma. Ambulante, ki jih večina stanovalcev obiskuje, ko potrebuje zdravniško oskrbo, so bile $\mathrm{z}$ vidika dostopnosti slabo ocenjene. Le $7 \%$ anketirancev je menilo, da so uradi za izplačevanje pokojnin samo nekaj minut hoje stran od doma, kar za starejše prebivalce ni ugodno, saj se običajno težje gibljejo (glej preglednico 2). 
Preglednica 2: Odgovori anketirancev glede bližine storitev in javnih dobrin v naselju Braamfischerville (\%)

\begin{tabular}{ll}
\hline Spremenljivke & Nekaj minut hoje stran \\
\hline trgovine Spaza & 86 \\
\hline postajališča za taksije & 80 \\
\hline osnovne šole & 78 \\
\hline avtobusna postajališča in postaje & 63 \\
\hline srednje šole & 38 \\
\hline formalne trgovine z živili & 38 \\
\hline ambulante & 31 \\
\hline vrtci & 18 \\
\hline uradi za izplačevanje pokojnin & 7 \\
\hline železniška postaja & 6
\end{tabular}

\section{Kakovost življenja v naselju Braamfischerville}

Mestna območja, na katerih prevladuje temnopolto prebivalstvo, in neformalna naselja so degradirana življenjska območja z neustrezno infrastrukturo ter $s$ slabimi družbenimi in rekreacijskimi objekti. Izrazita revščina je zlasti značilna za neformalna naselja (Westaway, 2006). Ministrstvo za stanovanjske zadeve je že leta 1968, ko je v Južnoafriški republiki še vladal apartheid, priznalo, da ima pokrajina, ki obdaja naselje, zelo pomembno vlogo pri njegovi vitalnosti, še zlasti v novih stanovanjskih naseljih. Poleg tega opredeljuje tudi nov življenjski standard, kar lahko vzbuja strah med prebivalci (Mohlala, 2002). V anketi, ki jo je leta 2000 izvedel mestni svet $\mathrm{v}$ Johannesburgu, so anketiranci nakazali, da se jim zdi slab (omejen) dostop do storitev in objektov sporen, prav tako pa tudi kakovost nudenja storitev (Westaway, 2006). V naselju Braamfischerville je večina storitev in infrastrukture pomanjkljiva ali pa slabo razvita. Prebivalci navajajo, da je mestni svet šele leta 2008 začel asfaltirati glavne ceste in območje urejati $s$ sajenjem dreves ob cestah. Brez parkov, ki bi omogočili rekreacijo, je to izredno pusto območje.

Vsi štirje sklopi stanovanj v okviru RDP v naselju Braamfischerville so bili zgrajeni v bližini rudniškega jalovišča. Prvi trije sklopi so bili zgrajeni $350 \mathrm{~m}$ od tega dejavnika zdravstvenega tveganja, zadnji pa samo $100 \mathrm{~m}$ stran, zaradi česar so hiše pristale v območju prašenja. Za povrh pri gradnji teh hiš niso uporabili prezračevalnih zidakov, zaradi česar morajo stanovalci okna nenehno odpirati, če želijo svoja stanovanja prezračiti. Posledično se $\mathrm{v}$ hišah nabira prah. Ti dejavniki lahko negativno vplivajo na zdravje stanovalcev. Poleg tega imajo hiše, zgrajene v prvem sklopu, azbestno streho brez stropov, kar prav tako ogroža zdravje stanovalcev.

Kakovost življenja na preučevanem območju je slaba tudi zaradi omejene velikosti tamkajšnjih stanovanj. Zaradi prevelikega

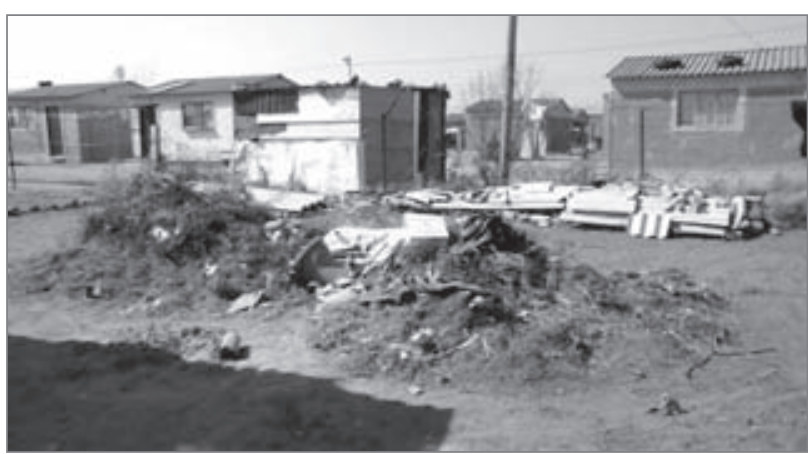

Slika 4: Hiša, ki je pogorela zaradi neustrezne električne napeljave (foto: Raeesa Moolla).

števila stanovalcev v eni hiši prihaja na tem območju do prenaseljenosti. $42 \%$ anketirancev je navedlo, da na $36 \mathrm{~m}^{2}$ živi od pet do deset ljudi, pri čemer stanovanje obsega samo en prostor odprtega tipa. Zaradi tega imajo stanovalci le malo zasebnosti, kar še dodatno slabša kakovost življenja.

\section{Sklep}

Čeprav stanovanja, zgrajena $\mathrm{v}$ okviru RDP, nudijo zavetje ljudem, ki so prej najverjetneje živeli v barakah ali ilegalnih bivališčih na tujih dvoriščih, razmere v teh naseljih še zdaleč niso popolne. $V$ tej študiji primera so anketiranci ostro kritizirali velikost hiš, zgrajenih v okviru RDP, kot tudi kuhinje in kopalnice (čeprav zadnje v manjši meri). To lahko pripišemo slabemu načrtovanju in prizadevanjem stanovanjskih organov, da čim bolj omejijo stroške gradnje teh stanovanj. Pritožbe so bile usmerjene tudi na strehe, okna in vrata, kar lahko povežemo s slabo kakovostjo obrtniških del in $\mathrm{z}$ omejevanjem stroškov investitorjev.

Zaradi visoke stopnje brezposelnosti in velikega deleža prebivalcev, ki mesečno zaslužijo le 1.500 ZAR (približno 200 USD) ali še manj, je v naselju Braamfisherville zelo pomembno, da se vse storitve in javne dobrine zagotovijo tako, da so prevozni stroški za stanovalce čim nižji. Na žalost pa je dejanski položaj drugačen, z izjemo postajališč za taksije. Prebivalci so navedli, da so druge oblike javnega prevoza (na primer avtobusna postajališča in železniške postaje) težje dostopne. Na preučevanem območju primanjkujejo javne dobrine, ki bi jih morala zagotoviti vlada (na primer srednje šole, vrtci, ambulante in uradi za izplačevanje pokojnin), poleg tega so anketiranci navajali, da do njih težko dostopajo.

Prav tako je sporna lokacija obravnavanih stanovanjskih naselij, zgrajenih v naselju Braamfisherville v okviru RDP, saj v njih niso zagotovili ustreznih javnih dobrin in storitev. Vsi štirje sklopi stanovanjskih naselij, zgrajenih v okviru RDP, so bili zgrajeni drug ob drugem nedaleč od jalovišča, okrog katerega se praši, kar lahko škoduje zdravju stanovalcev. Kakovost ži- 
vljenja na obravnavanem območju je nizka tudi zaradi omejene velikosti stanovanj. Zaradi prevelikega števila stanovalcev v hiši prihaja do prenaseljenosti, poleg tega pa stanovalci nimajo dovolj zasebnosti.

Čeprav stanovanja, zgrajena v okviru RDP, nekdanjim brezdomcem nudijo le minimalno osnovno nastanitev, večini stanovalcem zagotavljajo gotovo lastninsko pravico. Za izboljšanje kakovosti življenja $\mathrm{v}$ teh novozgrajenih naseljih bo morala vlada zagotoviti potrebne storitve in infrastrukturo. Tako bodo stanovanja primernejša za bivanje, stanovanjske skupnosti pa vzdržnejše. Vsekakor bi revnim morali zagotoviti več kot le streho nad glavo.

\section{Raeesa Moolla}

University of Johannesburg, Faculty of Science, Department of Geography, Environmental Management and Energy Studies, Auckland Park, Južnoafriška republika

E-pošta: aeesamoolla@gmail.com

\section{Nico Kotze}

University of Johannesburg, Faculty of Science, Department of Geography, Environmental Management and Energy Studies, Auckland Park, Južnoafriška republika

E-pošta: nicok@uj.ac.za

\section{Liz Block}

University of Johannesburg, Faculty of Science, Department of Geography, Environmental Management and Energy Studies, Auckland Park, Južnoafriška republika

E-pošta: eblock@uj.ac.za

\section{Viri in literatura}

Bhengu, X. (2008): Housing delivery to receive a boost from new state agency. Sowetan News, 3. 4. 2008, str. 16.

Bond, P., in Khosa, M. (ur.) (2002): An RDP policy audit. Pretoria, Human Sciences Research Council.

Cox, A. (2008): Innovative ways sought to house Alex residents. The Star Newspaper, 28. 4. 2008, str. 6.

Cross, C., Kok, P., Wentzel, M., in O'Donovan, M. (2005): Population and households in Johannesburg: Report to Johannesburg City Strategies. Pretoria, Human Sciences Research Council.

Donaldson, R., in Marais, L. (2002): Urban policy for urban change during transition: An introduction. V: Donaldson, R., in Marais, L. (ur.) Transforming rural and urban spaces in South Africa during the 1990s: Reform, restitution, restructuring, str. 179-202. Pretoria, Africa Institute of South Africa.

Fitchett, A. (2001): Contractor development through the provision of low-cost mass housing. Urban Forum, 12(3-4), str. 352-364. DOI: 10.1007/s12132-001-0011-9

Lazenby, K. (1988): Bewoningsbevrediging in die blanke woonhuissektor binne die munisipaliteit van Bloemfontein: ' $n$ Studie van proses, patrone en strategie. Doktorska disertacija. Bloemfontein, University of the Orange Free State.

Marais, L., Barnes, L., in Schoeman, J. (2002): A provincial comparison of post-apartheid housing policy and delivery: The Free State and Northern Cape as case study. V: Donaldson, R. \& Marais, L. (ur.) Transforming rural and urban spaces in South Africa during the 1990s: Reform, restitution, restructuring, str. 381-405. Pretoria, Africa Institute of South Africa.

Mehlomakulu, T., in Marais, L. (2000): Dweller perceptions of public and self-built homes: Some evidence from Mangaung (Bloemfontein). Journal of Family Ecology and Consumer Sciences, 27(2), str. 92-102.

Mohlala, T. (2002): A choice to move. Mail and Guardian Online Newspaper, 28. 9. 2002.

Moolla, H. (2008): Board member of City Parks (osebni vir, 28. 1 2008).

O'Leary, B. (2003): Changes in quality of life of Durban's residents between 1998 and 2002. Urban Health and Development Bulletin, 6(1-2), str. 35-39.

Pollack, M. (2003): SA's "greenest" RDP houses are being built in Atlantis. Dostopno na: http://www.capetown.gov.za/en/Pages/ RDPhousesarebuiltAtlantis.aspx (sneto 14. 9. 2008).

Pottie, D. (2003): Housing the nation: The politics of low-cost housing policy in South Africa since 1994. Politeia, 22(1), str. 119-143.

Rosenberger, I. K. (2003): Sustainable low-cost housing: A review of three low-cost housing developments in Gauteng Province. Magistrska naloga. Johannesburg, Rand Afrikaans University.

Sowman, M., in Urquhart, P. (1998): A place called home: Environmental issues and low-cost housing. Cape Town, University of Cape Town Press.

Thale, T. (2001): New plan for better housing. City of Johannesburg, 16 Nov. 2001. Dostopno na: http://www.joburgnews.co.za/ november/housing.stm (sneto 10. 8. 2008).

Turner, J. F. C. (1967): Barriers and channels for housing development in modernizing countries. Journal of American Institutional Planning, 23, str. 67-181.

Turner, J. F. C. (1976): Housing by people: Towards autonomy in building environments. London, Marion Byers.

Urad za stanovanja (2005): Pocket guide to South Africa 2005/2006: Housing. Pretoria.

Urad za stanovanja (2006): Annual report: Breaking new ground in housing development. Pretoria.

Westaway, M. S. (2006): A longitudinal investigation of satisfaction with personal and environmental quality of life in an informal South African housing settlement, Doornkop, Soweto. Habitat International, 30, str. 175-189. DOI: 10.1016/j.habitatint.2004.09.003 